\section{Vasil'ev A., Vasil'eva $\mathbf{N}$., Tupko $\mathbf{N}$.}

\title{
DEVELOPMENT OF COMBINED METHOD FOR ANALYSIS OF FINANCIAL RISKS OF INVESTMENT PROJECT
}

Запропоновано новий комплексний метод аналізу проектних ризиків, що є комбінацією методу сценаріїв та оцінки величин запасів беззбитковості і прийнятності проекту. За значеннями математичних очікувань цих запасів аналізуються інтегральний фінансовий ризик проекту в цілому і ризики проекту по його параметрам, будуються рейтинги проектних параметрів по спадаючій ризиків проекту.

Ключові слова: метод сщенарї̈, запаси беззбитковості і прийнятності проекту, рейтинги ризиків параметрів проекту.

\section{Introduction}

Analysis of investment risks is one of the fundamental problems of investment theory and practice [1-3]. Investment capital investments always refer to the future, often very distant, and the future is always subject to uncertainty. A risk is a partial uncertainty when some information about a future situation is known with a probability of less than one.

In general, the implementation of investment projects entails the emergence of three types of risk [4-7]:

1) own (individual) project risk - the risk that the actual results of the project may differ from those planned;

2) corporate (intra-firm) risk is associated with the influence that the course of the project implementation can have on the financial condition of the firm;

3) market risk characterizes the impact that the project implementation may have on the change in the company's share price, i. e. its market value.

In this article, only own (individual) financial risk of investment projects is investigated. Two different approaches to the definition of the project's own financial risk are used. The first traditional approach is mentioned above. The second approach is proposed by the authors of the article and consists in the following. Let's consider two sub-types of own financial risks of investment projects - the risk of loss and the risk of unacceptably low profitability. The risk of unprofitability of the project will be interpreted as the possibility of a negative value of the margin of the investment break-even of the project, and the risk of unacceptably low profitability of the project - as a possibility of a negative value of the project's investment acceptability margin $[8,9]$. Thus, in accordance with the second approach, the project's own financial risk is interpreted as the possibility of rejecting the actual results of the project from the critical ones for the worse.

\section{The object of research and its technological audit}

The objects of the research are the methods of quantitative analysis of the financial risk of investment projects.
Among the methods of this type that are used in practice, the most known are: the method of adjusting the discount rate, the method of reliable equivalents, the sensitivity analysis of project efficiency criteria, the scenario method, the decision tree method, the method of probability distributions of payment flows, the Monte Carlo simulation method [4, 6, 10]. Unfortunately, all these methods have significant drawbacks and limitations. Among them, there is no universal method suitable for a comprehensive risk assessment of most investment projects encountered in practice. Therefore, the problem of creating new or improving known methods of quantitative analysis of project risks is still relevant.

In this article, the authors propose a new method for analysis of project risks, which is a combination of the scenario method and analysis of the financial stability of the project. The scenario method is widely known and is often used in practice. As for the analysis of the financial sustainability of the project, this method was developed by the authors in previous works [8, 9] and is largely analogous to the analysis of the sensitivity of the project effectiveness criteria. In any case, both mentioned variants of analysis are single-factor, which is their main drawback. This shortcoming is unavoidable, because it is a reflection of the very essence of methods, the reverse side of the coin. The main shortcoming of the scenario method (the first component of the new combined method) is a significant element of subjectivism, manifested in the expert selection of probable scenarios for the development of the project and the probabilities of their implementation. The main drawbacks of the methods that form the new combination are not eliminated when combining. However, a certain benefit in the universality and effectiveness of the component methods is still observed. The scenario method is enriched by the ability to find critical values of design parameters and to determine the extent to which scenario values are remote from them, and the analysis of the financial stability margin of the project ceases to be a strictly deterministic method because gets the opportunity to find the mathematical expectations of the margin values for all project scenarios. In addition, as a result of the conjunction, the scenario method becomes suitable not only for assessing the integral financial risk of 
the project as a whole, but also for assessing the project risk by its main parameters.

\section{The aim and objectives of research}

The aim of research is development of a new combined method for analysis of project risks based on the integration of the scenario method into a single whole and the method of estimating the margin of financial stability of the project by its parameters created by the authors.

To achieve this aim, it is necessary to solve the following tasks:

1. To adapt the concept of the profitability levels of the investment project developed by the authors in their previous articles for the scenario method $[8,9]$.

2. To integrate the financial stability of the project by its parameters into the scenario method as an integral part of the analysis.

3. To adapt the analysis of the financial stability of the project according to the values of the project efficiency criteria for the scenario method.

4. Extend the scenario method to the case of an arbitrary flow of net operating revenues from the project.

\section{Research of existing solutions of the problem}

The scenario method, which is an integral part of the new combined method of analysis of project risks proposed by the authors of the article, is well known. It was considered by many authors (for example, [4, 6, 10], etc.). Typically, this method is used for investment projects in which the net operating income stream is a simple permanent annuity with a specified payment structure expressed through project parameters [4]. Investment projects with a similar structure are also investigated in this paper. However, in the new method proposed by the authors for each probable scenario of the project, not only the value of the resulting return indicator is traditionally calculated, but also the dynamic points of break-even and acceptability of the project [9], as well as the margin of its financial stability for each parameter. Then, based on the results of all scenarios not only the expected value of the resulting return indicator is calculated, but also the expected values of break-even points (acceptability) and financial stability margin of the project. As a result, in addition to assessing the overall financial risk of the project as a whole, the project risk estimates for each parameter are also obtained.

Based on the expected values of the financial stability of the project, it is possible to construct a rating of project parameters by decreasing the risk by analogy with the procedure for another known method for analysis of project risks-sensitivity analysis of project effectiveness criteria $[4,6,7,10]$.

It is possible also apply the new method proposed by the authors to investment projects with an arbitrary flow of payments. In this case, the project risk by its parameters can't be determined, because payment structure is unknown. But the integral financial risk of the project as a whole can be estimated in two ways:

- using standard deviation and coefficient of variation [7];

- with the help of relative margin of financial stabi-

lity of the project according to the values of efficiency criteria [8].

\section{Methods of research}

The methodological basis for the authors to create a new method for analysis of investment risks is a dynamic version of the analysis of the break-even production. The most innovative part of the new method is to estimate the values of the financial stability margin of the project. The margin of break-even (safety) of production were considered by many authors (for example, in $[5,10]$ ). However, all research on this issue was carried out exclusively within the framework of the traditional static break-even analysis without taking into account the time value of money. But, each investment project has a certain length in time. Therefore, when analyzing the profitability of a project, one can't ignore the concept of the time value of money. The concepts of the financial stability of the project should be based on a dynamic break-even analysis, in which the profit is replaced by one of the discounted project efficiency criteria (NPV, PI, IRR) that take into account the decline in the cost of project payments over time. The concepts of the investment breakeven margin and project acceptability for the dynamic case were first introduced in the previous works of the authors [8, 9].

The new method proposed by the authors explores the risks of the project in a comprehensive and systemic way. First, the integral financial risk of the project as a whole is examined, and secondly, the financial risk of the project is investigated for each of its main parameters. To analyze the integral financial risk of a project as a whole, two fundamentally different approaches are used within the proposed new method. The first approach is based on the traditional formulas of the scenario method [7], i. e. on the calculation of mathematical expectation, variance, standard deviation and coefficient of variation for the scenario values of the chosen project efficiency criterion (NPV, PI, IRR). The second approach is based on estimating the relative margin of financial stability of the project based on the values of the chosen efficiency criterion [8]. To analyze the financial risk of a project using its parameters, only the second approach is used. Moreover, in this case the margin of financial stability of the project is analyzed not according to the values of efficiency criteria, but by the values of the design parameter itself being investigated for risk [9]. Therefore, in this case, the second approach can be interpreted as a kind of «reverse analysis of the sensitivity of project efficiency criteria». Unlike the traditional version of the sensitivity analysis, the values of the project effectiveness criterion are first varied, and then the values of the corresponding deviations of the projected risk for the design parameter are estimated (i. e., in comparison with the classical sensitivity analysis everything is exactly the opposite).

At the same time, the concept of project financial risk in the first and second approaches is treated differently. Within the first (traditional) approach, the project's own risk is interpreted as the possibility of deviating its actual results from those expected [4]. In the second approach, based on the analysis of the financial sustainability of the project, let's treat the project loss risk by one of its parameters as the possibility of a negative value of the investment break-even margin for this parameter when the projected value of the projected risk parameter is 
worse than the break-even. Similarly, the risk of unacceptably low profitability of the project by one of its parameters will be understood as the possibility of a negative value of the margin of investment acceptability for this parameter (the scenario value of the parameter is worse than acceptable). In the sense of this interpretation, the smaller the positive margin for a project parameter, the greater the corresponding risk, and the more closely it is necessary to monitor the change in the values of this parameter. For comparison, in the traditional version of the sensitivity analysis, the greater the sensitivity (elasticity) of the efficiency criterion for the project parameter, the greater the risk of the project in this parameter.

It is useful to build ratings of design parameters by decreasing the corresponding risks (i. e., by increasing the size of margin) in order to identify the parameters that have the greatest potential threat to the financial success of the project. It is also possible to construct a matrix of sensitivity and predictability of project factors $[6,10]$, which in our case is more appropriately called a matrix of riskiness and predictability of project factors. Numerous experiments for model projects show that the ratings of design parameters by descending risk, constructed using the analysis of the financial stability of the project and the analysis of the sensitivity of the project efficiency criteria, are the same. But, the analysis of the financial stability of the project, in addition to ratings of project parameters, also provides another useful information for project developers. If the sensitivity analysis determines only the effect of each design parameter on the resulting indicator of project efficiency, the proposed method of estimating the values of the financial stability margin allows to determine the critical values of the project parameters and the degree of remoteness from them (i.e. the safety degree) of the specified scenario values. In addition, within the proposed approach, it is also possible to find the absolute and relative deviations of the average for all project scenarios of the value of each parameter from the average scenario value of the break-even point (or acceptability) of the project for this parameter.

Thus, the analysis of the financial stability of the project, which is an integral part of the combined method of analysis of project risks proposed by the authors, is more informative than the classical analysis of the sensitivity of the project effectiveness criteria.

\section{Research results}

Let's consider in more detail the new combined method of analysis of project risks based on the combination of the scenario method and the method of estimating the margin of financial stability of the project created by the authors based on its parameters. In the calculation formulas of both methods that form the combination, the values of the discounted project efficiency criteria are used.

It is most convenient to use the criteria NPV (Net Present Value) and PI (Profitability Index), which for the $k$-th probable project scenario are determined by the formulas $[4,7]$ :

$$
N P V_{k}=-I_{0}^{k}+\sum_{t=1}^{n_{k}} \frac{C F_{t}^{k}}{\left(1+i_{k}\right)^{t}}, k=\overline{1, m},
$$

$$
P I_{k}=\sum_{t=1}^{n_{k}} \frac{C F_{t}^{k}}{\left(1+i_{k}\right)^{t}}: I_{0}^{k}, k=\overline{1, m},
$$

where $k$ - the project scenario number, $m$ - the number of project scenarios; $i$ - the discount rate; $t$ - the number of the current project time period; $C F$ - amount of net income from the operation of the project; $I_{0}$ - initial investment in the project.

These project performance criteria are linked by the formulas:

$$
\begin{aligned}
& P I_{k}=1+\frac{N P V_{k}}{I_{0}^{k}}, k=\overline{1, m}, \\
& N P V_{k}=I_{0}^{k} *\left(P I_{k}-1\right), k=\overline{1, m} .
\end{aligned}
$$

So that from the value of one criterion one can easily switches to the value of the other.

Let's define the determining levels of its profitability for the $k$-th probable project scenario $[8,9]$ using criteria (1), (2).

I. Level of investment break-even of the project:

$$
N P V_{k} \geq 0\left(P I_{k} \geq 1\right), k=\overline{1, m} \text {. }
$$

II. Level of investment acceptability of the project:

$$
N P V_{k} \geq N P V_{*}>0\left(P I_{k} \geq P I_{*}>1\right), k=\overline{1, m},
$$

where $N P V_{*}\left(P I_{*}\right)$ - the lower limit is acceptable for the investor or project management project profitability values.

III. The actual profitability level of the project, determined by the flow of its payments set by the scenario condition:

$$
N P V=N P V_{k}\left(P I=P I_{k}\right), k=\overline{1, m} .
$$

In the framework of the analysis of financial sustainability of the project for its $k$-th scenario $(k=\overline{1, m})$, let's introduce the concepts of margin of investment break-even and acceptability according to project parameters. In this case, let's consider three cases:

- Homogeneous products are produced. The flow of net income from the operation of the project under the $k$-th scenario is a simple ordinary annuity [4, 7] with a known structure of payments, expressed in terms of the project parameters assigned to the scenario.

- Several types of products are produced. The flow of project payments is similar to the flow for case 6.1 .

- The amounts of payments for the project flow are arbitrary.

Let's consider each of these cases in more detail.

6.1. Analysis of the investment project risks for the rental flow of payments and production of homogeneous products. Let the rental flow of net proceeds from the operation of the project according to its $k$-th probable scenario look like:

$$
C F_{t}^{k}=\left(Q_{k}\left(c_{k}-v_{k}\right)-F C_{k}-d e p_{k}\right)\left(1-\tau_{k}\right)+d e p_{k}, k=\overline{1, m},
$$

where $Q$ - the volume of production (sales) of project products for 1 period; $c$ - unit price; $v$ - specific variable production costs; $F C$ - total fixed production costs for 1 period of the project; dep - the amount of depreciation 
deductions for 1 period of the project; $k$ - the project scenario number, $m$ - the number of project scenarios.

Then, in order to calculate the value of the $N P V$ criterion for the $k$-th probable scenario of the project, let's apply the formula from [4], considering the liquidation value of the project equipment equal to zero:

$$
\begin{aligned}
& N P V_{k}=-I_{0}^{k}+\left(\left(Q_{k}\left(c_{k}-v_{k}\right)-F C_{k}-d e p_{k}\right)\left(1-\tau_{k}\right)+d e p_{k}\right) \times \\
& \times a\left(n_{k}, i_{k}\right), k=\overline{1, m},
\end{aligned}
$$

where the coefficient of discounting the unit rent [7] is:

$$
a\left(n_{k}, i_{k}\right)=\left(1-\left(1+i_{k}\right)^{-n_{k}}\right) / i_{k} .
$$

Let's first consider the analysis of the integral financial risk of the project as a whole according to the scenario method in the traditional form [7]. Let's find the mathematical expectation, variance, standard deviation and coefficient of variation for the scenario values of the $N P V$ project efficiency criterion:

$$
\begin{aligned}
& M(N P V)=\sum_{k=1}^{m} N P V_{k} \times p_{k}, \\
& D(N P V)=\sum_{k=1}^{m}\left(N P V_{k}-M(N P V)\right)^{2} \times p_{k}, \\
& \sigma(N P V)=\sqrt{D(N P V)}, \\
& C V(N P V)=\frac{\sigma(N P V)}{M(N P V)},
\end{aligned}
$$

where scenario values of the $N P V$ criterion are calculated using formula (9), $m$ - the number of considered probable project scenarios.

Now, for each likely project scenario, let's estimate the project's financial risk by its parameters by analyzing the project's financial stability margin by these parameters. Before entering the concept of margin, let's find the critical values of the project parameters corresponding to the lower limits of the first and second levels of profitability for each project scenario.

First, let's find the values of the parameters of the project flow of payments (8) corresponding to the lower boundary of the level I of the project's break-even, from the following equations:

$$
N P V_{k}=0, k=\overline{1, m},
$$

where scenario values of the $N P V$ criterion are found from the formula (9).

Solving equation (15) for the parameter of the volume of production (sales) for each probable project scenario and assuming the values of the remaining design parameters to be fixed, let's find the dynamic break-even point of the project in this parameter:

$$
\begin{aligned}
& Q_{k}^{0}=\frac{1}{c_{k}-v_{k}}\left(\frac{1}{1-\tau_{k}}\left(\frac{I_{0}^{k}}{a\left(n_{k}, i_{k}\right)}-d e p_{k}\right)+F C_{k}+d e p_{k}\right), \\
& k=\overline{1, m} .
\end{aligned}
$$

Let's find break-even values of other parameters of the project from the equations (15) - unit prices, unit production costs, total fixed production costs for one project period:

$$
\begin{aligned}
& c_{k}^{0}=v_{k}+\frac{1}{Q_{k}}\left(\frac{1}{1-\tau_{k}}\left(\frac{I_{0}^{k}}{a\left(n_{k}, i_{k}\right)}-d e p_{k}\right)+F C_{k}+d e p_{k}\right), \\
& k=\overline{1, m}, \\
& v_{k}^{0}=c_{k}-\frac{1}{Q_{k}}\left(\frac{1}{1-\tau_{k}}\left(\frac{I_{0}^{k}}{a\left(n_{k}, i_{k}\right)}-d e p_{k}\right)+F C_{k}+d e p_{k}\right), \\
& k=\overline{1, m} \\
& F C_{k}^{0}=Q_{k}\left(c_{k}-v_{k}\right)-\frac{1}{1-\tau_{k}}\left(\frac{I_{0}^{k}}{a\left(n_{k}, i_{k}\right)}-d e p_{k}\right)-d e p_{k}, \\
& k=\overline{1, m} .
\end{aligned}
$$

Now let's find the dynamic break-even point of the project at the discount rate. It is the root of equation (1) for the rate parameter (in this case, the structure of payments is unimportant):

$$
N P V_{k}\left(i_{k}\right)=-I_{0}^{k}+\sum_{t=1}^{n_{k}} \frac{C F_{t}^{k}}{\left(1+i_{k}\right)^{t}}=0, k=\overline{1, m} .
$$

Obviously, the break-even value of the rate is equal to the value of one of the main criteria of the project's effectiveness - the internal rate of return of the project for its $k$-th scenario, i. e.:

$$
i_{k}^{0}=I R R_{k}, k=\overline{1, m} .
$$

Let's find the critical values of the design parameters corresponding to the lower boundary of the level II of the project's investment acceptability. These values are determined from the equations:

$$
N P V_{k}=N P V_{*}, k=\overline{1, m},
$$

where the lower bound of acceptability is given in (6), and the left-hand sides of equations (22) have the form (9)

Solving equations (22) with respect to the production volume (sales) parameter with fixed values of the remaining parameters, let's obtain [9]:

$$
\begin{aligned}
& Q_{k}^{*}=\frac{1}{c_{k}-v_{k}}\left(\frac{1}{1-\tau_{k}}\left(\frac{I_{0}^{k}+N P V_{*}}{a\left(n_{k}, i_{k}\right)}-d e p_{k}\right)+F C_{k}+d e p_{k}\right), \\
& k=\overline{1, m} .
\end{aligned}
$$

Let's name the volume (23) of the production (sales) of the project's products for the same period in accordance with the k-th project scenario by the dynamic acceptability point of the project in this parameter. If the level of acceptable profitability of the project given in (6) is increased, then the volumes (23) will also grow.

Let's find the dynamic points of project acceptability for other main design parameters from the equations (22):

$$
\begin{aligned}
c_{k}^{*} & =v_{k}+\frac{1}{Q_{k}}\left(\frac{1}{1-\tau_{k}}\left(\frac{I_{0}^{k}+N P V_{*}}{a\left(n_{k}, i_{k}\right)}-d e p_{k}\right)+F C_{k}+d e p_{k}\right), \\
k & =\overline{1, m},
\end{aligned}
$$




$$
\begin{aligned}
& v_{k}^{*}=c_{k}-\frac{1}{Q_{k}}\left(\frac{1}{1-\tau_{k}}\left(\frac{I_{0}^{k}+N P V_{*}}{a\left(n_{k}, i_{k}\right)}-d e p_{k}\right)+F C_{k}+d e p_{k}\right), \\
& k=\overline{1, m} \\
& F C_{k}^{*}=Q_{k}\left(c_{k}-v_{k}\right)-\frac{1}{1-\tau_{k}}\left(\frac{I_{0}^{k}+N P V_{*}}{a\left(n_{k}, i_{k}\right)}-d e p_{k}\right)-d e p_{k}, \\
& k=\overline{1, m}
\end{aligned}
$$

Dynamic points of project acceptability for each scenario at discount rates are found as the roots of the following equations for the rate parameter:

$$
N P V_{k}\left(i_{k}\right)=-I_{0}^{k}+\sum_{t=1}^{n_{k}} \frac{C F_{t}^{k}}{\left(1+i_{k}\right)^{t}}=N P V_{*}, k=\overline{1, m} .
$$

The root of equation (27), by analogy with the solution of (21), will be called [8] the internal rate of acceptable return (IRAR) for its $k$-th scenario, i. e.:

$$
i_{k}^{*}=I R A R_{k}, k=\overline{1, m} .
$$

IRAR is a new criterion for the financial effectiveness of the project, proposed by the authors of the article in their previous works. Unlike the IRR criterion, it depends not only on the project's payment flow, but also on the level of acceptable profitability of the project specified in (6): the higher the specified level, the lower the IRAR value.

Let's find the expected value for all project scenarios of the dynamic breakeven point of the project in terms of the volume of production (sales) of the project products in one period, using the values (16):

$$
M\left(Q^{0}\right)=\sum_{k=1}^{m} Q_{k}^{0} * p_{k}
$$

Quite similarly (29), it is possible to find the expected values of the break-even points of the project in terms of $c$ (unit price), $v$ (specific variable production costs), $F C$ (total constant production costs for one period). At the discount rate, we actually get the expected value for all scenarios of the IRR effectiveness criterion:

$$
M\left(i^{0}\right)=M(\operatorname{IRR})=\sum_{k=1}^{m} I R R_{k} * p_{k},
$$

so by this parameter, we obtain an estimate of the integral risk of the project as a whole, alternative for estimation (11). If desired, it is possible to find not only the mathematical expectation of the IRR project (30), but also the variance, standard deviation and the coefficient of IRR variation by analogy with formulas (12)-(14).

Using the values (23) of the project's acceptability points for each scenario in terms of the volume of production (sales), let's find the expected value of the project's dynamic acceptability point for this parameter:

$$
M\left(Q^{*}\right)=\sum_{k=1}^{m} Q_{k}^{*} * p_{k}
$$

Similarly, let's determine the expected values of the dynamic points of project acceptability in terms of parameters - price, specific variables and total fixed costs.
At the rate of discounting, an estimate of the project's integrated risk is again obtained as a whole based on a new criterion for the effectiveness of the IRAR project:

$$
M\left(i^{*}\right)=M(I R A R)=\sum_{k=1}^{m} I R A R_{k} \times p_{k} .
$$

Let's pass to definition of concepts of margin of financial stability of the project. First, let's introduce the concept of the margin of the investment break-even project by its parameters.

Absolute margin of the investment break-even for one project period for its $k$-th scenario in terms of the volume of production (sales) of products is:

$$
\alpha_{Q_{k}}=Q_{k}-Q_{k}^{0}, k=\overline{1, m},
$$

relative:

$$
\beta_{Q_{k}}=\frac{Q_{k}-Q_{k}^{0}}{Q_{k}}=1-\frac{Q_{k}^{0}}{Q_{k}}, k=\overline{1, m},
$$

where the values of break-even points are taken from (16).

The mathematical expectations of this margin are equal:

$$
\begin{aligned}
& M\left(\alpha_{Q}\right)=M(Q)-M\left(Q^{0}\right), \\
& M\left(\beta_{Q}\right)=1-M\left(Q^{0} / Q\right), \\
& M(Q)=\sum_{k=1}^{m} Q_{k} \times p_{k} ; M\left(Q^{0} / Q\right)=\sum_{k=1}^{m} \frac{Q_{k}^{0}}{Q_{k}} \times p_{k} .
\end{aligned}
$$

If the values (35), (36) are positive, then the project has some «safety margin» in the financial plan. The larger the amount of margin (35), (36), the more stable the project from the financial point of view, and the less the risk of loss of the project in terms of production (sales) of products.

Analogously (35), (36), it is possible to define the concepts of absolute and relative margin of the project's investment breakeven in terms of parameters - price, specific variables and total fixed costs, as well as the expected values of this margin for all project scenarios. After this, it is possible to build a rating of project parameters by decreasing the risk of its loss. To do this, it is necessary to order the design parameters by increasing the expected values of their relative margin. Based on the rating of unprofitability risks of design parameters, it is possible to construct, by analogy with the sensitivity analysis of performance criteria, a matrix of riskiness and predictability of project factors that has three (or four) risk areas with appropriate recommendations for management of the investment project $[6,7,10]$. At the discount rate, an estimate of the project's integral risk as a whole is again obtained. The relative margin of the project's investment break-even in this parameter coincides with the corresponding margin according to the values of the IRR efficiency criterion:

$$
\beta_{i_{k}}=\frac{i_{k}^{0}-i_{k}}{i_{k}^{0}}=\frac{I R R_{k}-C C_{k}}{I R R_{k}}=1-\frac{C C_{k}}{I R R_{k}}, k=\overline{1, m}
$$

where the discount rate for the $k$-th scenario of the project is equal to the scenario value of the capital of the project CC (Cost of Capital). 
Now let's define the concept of investment acceptability margin of the project by its parameters for the $k$-th scenario.

Absolute margin of investment acceptability for one period of the project for its $k$-th likely scenario in terms of the volume of production (sales) of products is:

$$
\eta_{Q_{k}}=Q_{k}-Q_{k}^{*}, k=\overline{1, m}
$$

relative:

$$
\gamma_{Q_{k}}=\frac{Q_{k}-Q_{k}^{*}}{Q_{k}}=1-\frac{Q_{k}^{*}}{Q_{k}}, k=\overline{1, m}
$$

where the values of the acceptability points are taken from (23).

Analogously to (35), (36) obtain:

$$
\begin{aligned}
& M\left(\eta_{Q}\right)=M(Q)-M\left(Q^{*}\right), \\
& M\left(\gamma_{Q}\right)=1-M\left(Q^{*} / Q\right), \\
& M\left(Q^{*} / Q\right)=\sum_{k=1}^{m} \frac{Q_{k}^{*}}{Q_{k}} \times p_{k} .
\end{aligned}
$$

In the same way, it is possible to define the concepts of absolute and relative margin of the project's investment acceptability by parameters - price, specific variables and total fixed costs, as well as the expected values of these margin. Having located the project parameters by increasing the expected values of their relative margin of investment acceptability, we get a rating of the project parameters by decreasing the risk of its unacceptably low profitability. At the discount rate, the relative margin of the project's investment acceptability coincides with the corresponding margin according to the values of the IRAR efficiency criterion:

$$
\gamma_{i_{k}}=\frac{i_{k}^{*}-i_{k}}{i_{k}^{*}}=\frac{I R A R_{k}-C C_{k}}{I R A R_{k}}=1-\frac{C C_{k}}{I R A R_{k}}, k=\overline{1, m},
$$

Remark 1. In addition to the relative margin of financial stability of the project by its parameters of the form (34), (40), one can also consider the relative margin of the expected values of the design parameters of the type:

$$
\begin{aligned}
& \mu_{Q}=\frac{M(Q)-M\left(Q^{0}\right)}{M(Q)}=1-\frac{M\left(Q^{0}\right)}{M(Q)}, \\
& \delta_{Q}=\frac{M(Q)-M\left(Q^{*}\right)}{M(Q)}=1-\frac{M\left(Q^{*}\right)}{M(Q)} .
\end{aligned}
$$

By the values of these margin, it is possible to build the corresponding ratings of project parameters by decreasing the risk of the project.

6.2. The case of the production of several types of project products. In the case of multi-nomenclature production and the rent flow of net income from the project, instead of formula (9) let's use the formula:

$$
\begin{aligned}
& N P V_{k}=-I_{0}^{k}+\left(\left(A_{k}-V C_{k}-F C_{k}-d e p_{k}\right)\left(1-\tau_{k}\right)+d e p_{k}\right) \times \\
& \times a\left(n_{k}, i_{k}\right), k=\overline{1, m} .
\end{aligned}
$$

In the formula (47) $A$ - total revenue for one period from the sale of all types of project products, and $V C$ total variable costs for one project period. Equating the expressions (47) to zero and solving the obtained equations with respect to the total revenue parameter:

$$
\begin{aligned}
& A_{k}^{0}=\frac{1}{1-\tau_{k}}\left(\frac{I_{0}^{k}}{a\left(n_{k}, i_{k}\right)}-d e p_{k}\right)+V C_{k}+F C_{k}+d e p_{k}, \\
& k=\overline{1, m} .
\end{aligned}
$$

Similarly, let's find the dynamic break-even points of the project for $V C$ and $F C$ parameters:

$$
\begin{aligned}
& V C_{k}^{0}=A_{k}-\frac{1}{1-\tau_{k}}\left(\frac{I_{0}^{k}}{a\left(n_{k}, i_{k}\right)}-d e p_{k}\right)-F C_{k}-d e p_{k}, \\
& k=\overline{1, m}, \\
& F C_{k}^{0}=A_{k}-\frac{1}{1-\tau_{k}}\left(\frac{I_{0}^{k}}{a\left(n_{k}, i_{k}\right)}-d e p_{k}\right)-V C_{k}-\operatorname{dep}_{k}, \\
& k=\overline{1, m} .
\end{aligned}
$$

The dynamic break-even point of the project at the discount rate is still given by formula (21).

The expected value for all project scenarios of the dynamic break-even point of the project in terms of total revenue is:

$$
M\left(A^{0}\right)=\sum_{k=1}^{m} A_{k}^{0} \times p_{k} .
$$

Similarly, let's find the expected values of break-even points of the project in terms of $V C$ and $F C$ parameters.

In complete analogy with the case 6.1 , it is possible to define the concepts of absolute and relative reserves of the investment break-even and acceptability of the project for its $k$-th probable scenario by parameters - total revenue from product sales, total fixed costs for 1 project period, total variable costs for 1 project period, discount rate. It is also possible to find the expected values of these reserves. The integrated financial risk of the project can be assessed in two ways: using the standard formulas (11)-(14) of the scenario method and by analyzing the financial sustainability of the project based on the PI or IRR efficiency criteria.

6.3. The case of the project flow with arbitrary payment values. For such payment flow, the values of the $N P V$ criterion for the $k$-th probable project scenario are calculated using formula (1). The only parameter by which it is possible to investigate the financial sustainability of a project is the discount rate. But for this parameter, the margin coincides with the margin according to the values of IRR and IRAR efficiency criteria.

Thus, for case 6.3 , only the integral risk of the project can be estimated using formulas (11)-(14) or by using relative reserves based on the values of IRR, IRAR, and PI criteria. For example, for the PI criterion, the relative margin of the project's investment break-even for its $k$-th probable scenario is:

$$
\chi_{k}=\frac{P I_{k}-1}{P I_{k}}=1-\frac{1}{P I_{k}}, k=\overline{1, m},
$$

where the values of the $P I$ criterion for a given scenario flow of payments are found by the formula (2). The relative margin of the project's investment acceptability for its $k$-th likely scenario is: 


$$
\xi_{k}=\frac{P I_{k}-P I_{*}}{P I_{k}}=1-\frac{P I_{*}}{P I_{k}}, k=\overline{1, m},
$$

where the lower limit of acceptable profitability is given in (6). It is possible to find the expected values of these reserves and use them to assess the integrated risk of the project. In the case of 6.3 , it is impossible to build ratings of parameters by descending risk, but the integrated risk of the project is evaluated in a complex manner, i.e. more systemically and comprehensively in comparison with the classical method of scenarios.

Remark 2. If the likelihood of the implementation of the baseline scenario of the project significantly prevails over the probabilities of the remaining scenarios, it is advisable to construct project parameter ratings by increasing their relative reserves also for the base (most probable) scenario, and not just the project as a whole.

\section{SWOT analysis if research results}

Strengths. The new combined method of risk analysis of the investment project proposed by the authors of the article combines two methods - the scenario method and the method of estimating the margin of financial stability of the project, developed by the authors in previous articles. As a result of this association, it became possible to simultaneously assess the integral risk of the project as a whole and the risks of the project in its main parameters. Thus, the project's financial risk assessment using the new method is carried out in a comprehensive and systemic manner.

Weaknesses. The new risk analysis method of the investment project proposed in the article has the same basic drawback as for the classical variant of the scenario method: variants of the project development scenarios and the probability of their implementation are chosen expertly, i.e. subjectively. In addition, the laboriousness of calculating the required estimates has increased. However, in the case of software implementation of the method on a computer, this disadvantage is not significant.

Opportunities. The formula of the static variant of risk analysis are obtained as a special case at zero discount rate from the formulas derived in the article. For small time intervals (less than a year), this variant of analysis is completely correct, because for this time the value of money will not have time to change much.

Threats. The potential threat is the emergence of a new powerful universal method for analysis of design risks, lacking the main shortcomings of existing methods and applicable, in particular, in the case of a strong relationship between two or more factors of the project.

\section{Conclusions}

1. The concept of profitability levels of the investment project, developed by the authors in previous works $[8,9]$, is adapted for the scenario method. The essence of adaptation is that in the new combined method the levels of profitability I-III are set in (5)-(7) separately for each probable scenario of the investment project. At the same time, the lower limit of the profitability values acceptable to the investor or project management in (6) is common for all scenarios, because It is known with a probability equal to one.

2. An estimation of absolute and relative margin of financial stability of the project on its basic parameters is realized in a new method for each probable scenario of the investment project. Thus, the analysis of the financial stability of the project by its parameters organically «fits» into the structure of the scenario method.

3. For each probable scenario of the investment project, the values of integrated efficiency indicators - PI, IRR, IRAR are calculated. Then there are the relative margin of efficiency criteria by their values [8] and the mathematical expectations of these margin for all project scenarios. All this allows to evaluate the integral risk of the project as a whole, alternative to the traditional evaluation using formulas (11)-(14).

4. The new method for evaluating project risks developed by the authors is applicable not only for rental, but also for arbitrary project payment flows. However, in this case it is impossible to assess the financial risks of the project by its main parameters, and it is possible to obtain estimates only of the integral risk of the project as a whole.

\section{References}

1. Sharpe, W. Investments [Text] / W. Sharpe, G. J. Alexander, J. W. Bailey. - Ed. 6. - Prentice Hall, 1998. - 962 p.

2. Fabozzi, F. J. Investment Management [Text] / F. J. Fabozzi. Ed. 2. - Prentice Hall, 1998. -837 p.

3. Lee, C. F. Corporate Finance: Theory, Method, and Applications [Text] / C. F. Lee, J. E. Finnerty. - Harcourt College Pub, 1989. $-800 \mathrm{p}$.

4. Lukasevich, I. Ya. Analiz finansovyh operatsii. Metody, modeli, tehnika vychislenii [Text]: Handbook / I. Ya. Lukasevich. Moscow: Finansy, YuNITI, 1998. - 400 p.

5. Lukasevich, I. Ya. Finansovyi menedzhment [Text]: Handbook I. Ya. Lukasevich. - Ed. 2. - Moscow: Eksmo, 2010. - 768 p.

6. Grachiova, M. V. Risk-analiz investitsionnogo proekta [Text] / M. V. Grachiova. - Moscow: YuNITI, 2001. - 351 p.

7. Vorkut, T. A. Proektnyi analiz [Text] / T. A. Vorkut. - Kyiv: UTsDK, 2000. - 440 p.

8. Vasiliev, A. Reserves and limits of investment break even and acceptability of the project by values of the indicators of efficiency [Text] / A. Vasiliev, N. Vasilieva // Ekonomika ta derzhava. - 2015. - No. 4. - P. 28-32.

9. Vasilyev, A. Levels of return, reserves of investment breakeven and acceptability of the project [Text] / A. Vasilyev, N. Vasilyeva, N. Tupko // Scientific Bulletin of the Odessa National Economic University. - 2014. - No. 10. - P. 51-63.

10. Volkov, I. M. Proektnyi analiz [Text]: Handbook / I. M. Volkov, M. V. Grachiova. - Moscow: Banki i birzhi, YuNITI, 1998 - 423 p.

\section{РАЗРАБОТКА КОМБИНИРОВАННОГО МЕТОДА АНАЛИЗА ФИНАНСОВЫХ РИСКОВ ИНВЕСТИЦИОННОГО ПРОЕКТА}

Предложен новый комплексный метод анализа проектных рисков, являющийся комбинацией метода сценариев и оценки величин запасов безубыточности и приемлемости проекта. По значениям математических ожиданий этих запасов анализируются интегральный финансовый риск проекта в целом и риски проекта по его параметрам, строятся рейтинги проектных параметров по убыванию рисков проекта.

ключевые слова: метод сценариев, запасы безубыточности и приемлемости проекта, рейтинги рисков параметров проекта.

Vasil'ev Alexander, PhD, Associate Professor, Department of Optimal Control and Economic Cybernetics, Odessa I. I. Mechnikov National University, Ukraine, e-mail: av5111955@gmail.com, ORCID: http://orcid.org/0000-0002-3826-4883

Vasil'eva Nataliia, PhD, Associate Professor, Department of Higher Mathematics, Odessa State Academy of Civil Engineering and Architecture, Ukraine, ORCID: https://orcid.org/0000-0002-2708-414X

Tupko Natalia, PhD, Associate Professor, Department of Higher and Computational Mathematics, National Aviation University, Kyiv, Ukraine, e-mail: natupko@ukr.net, ORCID: http://orcid.org/00000003-0625-3271 